\title{
Imaging of Pregnancy Associated Breast Cancer
}

\author{
LAMIAA M.B. HASHEM, M.D.*; AHMED A.M. ABDELMAWLA, M.D.** and \\ AMR FAROUK I. MOUSTAFA, M.D.*** \\ The Department of Radiology, Faculty of Medicine* and National Cancer Institute***, Cairo University, \\ The Department of Surgical Oncology, National Cancer Institute, Cairo University**
}

\begin{abstract}
Background: Pregnancy-Associated Breast Cancer (PABC) is breast cancer presenting either during pregnancy or in the first postpartum year.

Aim of Study: The purpose of this study was to calculate the incidence of pregnancy associated breast cancer in patients presenting with clinically palpable masses during pregnancy or first postpartum year and to evaluate the role of sonomammography in the diagnosis of pregnancy associated breast cancer.

Patients and Methods: The study included 100 female patients with clinically palpable breast masses discovered during pregnancy and first year of lactation. All patients were evaluated by Ultrasound. Mammography was only performed on 23 patients. Mammographic and sonographic findings were evaluated retrospectively. No further diagnostic evaluation was done in case of benign radiological findings, yet biopsy was the next step performed if findings were suspicious.
\end{abstract}

Results: In total, 100 women were enrolled in this study; the mean age of this study population was 29 years. Among the studied cases only 15 cases $(n=15 / 100,15 \%)$ were malignant, their age ranged from 26 years to 40 years with average 34.6 , four of them $(n=4 / 15)$ were presented by right breast palpable lumps and $11(\mathrm{n}=11 / 15)$ by left breast palpable lumps. Ultrasound helped to classify 2 cases $(n=2 / 15)$ as BIRADS 4 and the rest $(n=13 / 15)$ as BIRADS 5 . Ultrasound guided biopsy was then performed for the 15 patients confirming their malignant nature.

Conclusion: Even though the majority of the pregnancyassociated breast masses are benign; a strict evaluation of any lesion is still required to exclude malignancy.

Key Words: Pregnancy - Lactation - Breast cancer - PABC - Ultrasound-Pregnancy-associated breast masses.

\section{Introduction}

PREGNANCY-Associated Breast Cancer (PABC) is breast cancer presenting either during pregnancy

Correspondence to: Dr. Lamiaa M.B. Hashem, The Department of Radiology, Faculty of Medicine, Cairo University or in the first postpartum year. It affects around 1 out of 3000 pregnant women and is considered the second most frequent malignancy affecting pregnancy [1].

The average age of women diagnosed with PABC is 32 to 38 years. Among all cases of breast cancer, only $6.5 \%$ affect women with age under 40 years. As more women are postponing childbearing, and breast cancer is increasing due to screening, more diagnoses of PABC are predicted [2-4].

Palpable mass is the usual presentation of breast cancers in pregnancy, and most breast cancers in patients under 40 years. PABC presents at an advanced stage with large sized lesions and has an increased percentage of reported hormone receptornegative tumors $[2,5]$.

The aim of our study was to calculate the incidence of pregnancy associated breast cancer in patients presenting with clinically palpable masses during pregnancy or first postpartum year and to evaluate the role of sonomammography in the diagnosis of pregnancy associated breast cancer.

\section{Patients and Methods}

This study included 100 cases presented during the 3-year period between 2014 and 2017 with clinically palpable breast masses discovered during pregnancy and first year of lactation to outpatient clinic at Khartoum Breast Care Center (Sudan), their ages ranged from 18-41 years (mean age 29). Patients were submitted to the following:

\section{I- Clinical history and examination:}

Full history taking was done including age and clinical presentation (palpable lump discovered 
during pregnancy or ${ }^{1 \text { st }}$ year of lactation) with dedicated examination.

\section{II- Imaging procedures:}

All patients $(n=100 / 100)$ underwent B-mode ultrasound examination including real-time sonography and color Doppler imaging of the area of concern. We used an ultrasound device of GE Healthcare (LOGIQ E5 with XD clear premium ultrasound) with a superficial linear $12 \mathrm{MHz}$ probe.

A standard two-view mammogram was obtained in only 23 patients $(n=23 / 100)$. Mammograms were done using the digital mammography system (GE Senographe 2000D full-field digital mammography system from GE Healthcare; Chalfont St-Giles, UK).

Mammographic and sonographic findings were evaluated retrospectively.

\section{Image analysis and interpretation of Sono- mammography:}

- Ultrasound: Each lesion was evaluated whether mass, simple cyst, complicated cyst or area of parenchyma distortion. Axillary lymph nodes were also evaluated.

- Mammography: Each lesion was evaluated regarding the site, type (mass, architectural distortion, asymmetry, calcifications).
- If findings are benign no further diagnostic evaluation was done but if they are suspicious biopsy was performed.

- BIRADS category of each lesion was determined according to the BIRADS atlas 2018, guided by the results of clinical data and sonomammographic findings but blind to final pathologic diagnosis.

\section{Results}

100 female patients with clinically palpable lumps discovered during pregnancy and first year of lactation were included in our study. Patients' ages ranged from 18 to 41 years with a mean age 29 years.

15 cases $(n=15 / 100)$ were malignant and patients' age ranged from 26 years to 40 years with average 34.6 year old. Four of them $(n=4 / 15)$ were presented by right breast palpable lumps and 11 $(n=11 / 15)$ by left breast palpable lumps.

Imaging findings were as follow: 2 cases $(\mathrm{n}=$ 2/15) were suspicious for malignancy and classified as BI-RADS 4 by ultrasound, and $13(n=13 / 15)$ as BI-RADS 5, all underwent further mammography study except 1 patient in early pregnancy underwent sonography only. True cut biopsy confirmed the pathological diagnosis in all the 15 cases. Pathology results were as follow: 2 cases were grade 1 IDC, 2 cases were grade 2 IDC and 11 cases were grade 3 IDC Fig. (1). (IDC: Invasive Ductal Carcinoma).

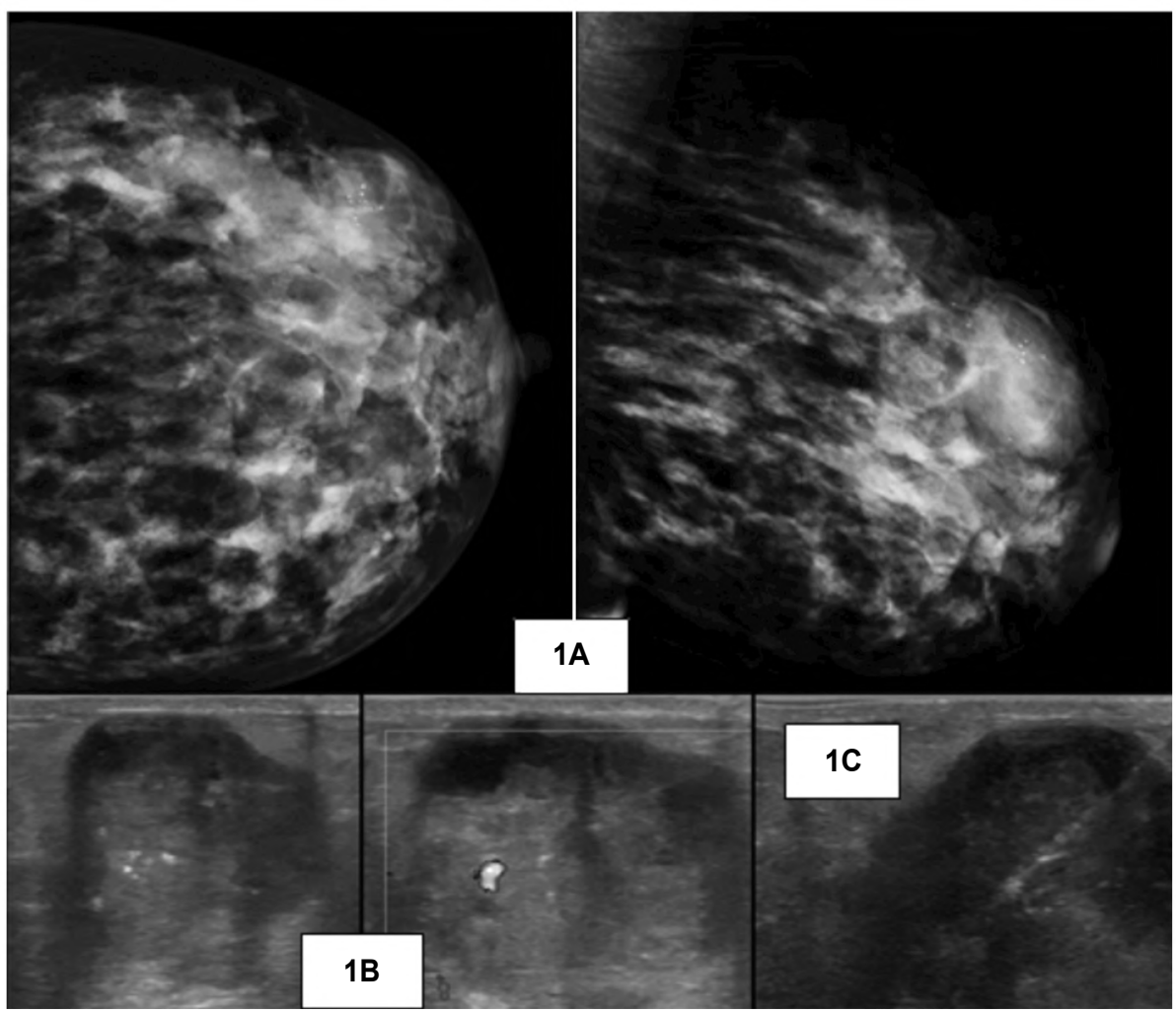

Fig. (1): (A, B \& C): 36 years old lactating woman presented with left breast palpable non painful lump. (A) Left breast mammogram (cranio-caudal \& medio-lateral oblique views) showed left UOQ rather well defined isodense mass lesion with calcific foci within. (B) Sonography showed a heterogeneous isoechoic mass with echogenic foci \& superficial cystic component at 1 O'clock (site of clinical concern and mammographically detected lesion). (C) US guided biopsy core biopsy images. Histopathology revealed invasive duct carcinoma grade III. 


\section{Discussion}

Pregnancy-associated breast cancer is generally considered an uncommon occasion. The average age at the time of presentation does not seem to change impressively across studies, and ran of from 33 to 36 years $[6,7]$. In our study the patients' age ranged from 26 years to 40 years with average of 34.6.

At the first obstetric visit, it is both basic and very important to perform a thorough breast examination and also encourge patients to proceed with self-breast examination all through pregnancy. Any discovered mass during pregnancy or lactation should be thoroughly assessed and examined by breast ultrasound. Ultrasound can help characterize the mass and recognize if there is any concerning features. If the sonographic results seem suspicious mammography should be performed followed by a core biopsy for pathologic assessment [8-10] Many women with breast cancer discovered during pregnancy are in advanced stages Fig. (2) and thorough evaluation of possible metastasis is mandatory [2].

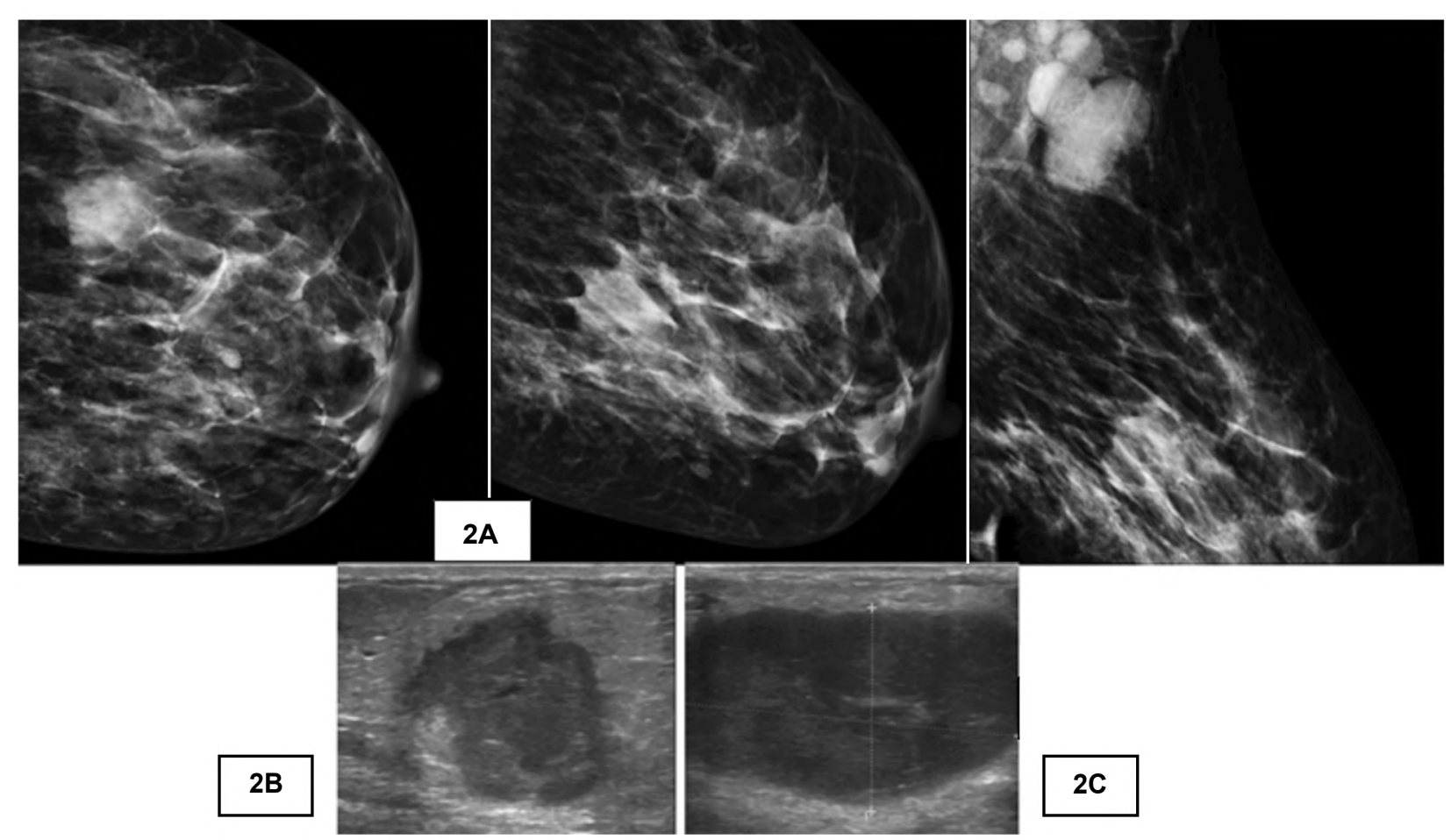

Fig. (2): (A, B \& C): 33 years old lactating woman presented with left breast palpable lump. (A) Left breast mammogram (cranio-caudal \& medio-lateral oblique views) showed left UOQ partially ill-defined isodense mass lesion. (B) Sonography showed an ill-defined isoechoic mass at 2 O'clock (area of clinical and mammographic concern). (C) US images of the left axilla showed pathologically enlarged axillary lymph node with effaced hilum. Histopathology revealed invasive duct carcinoma grade III.

Women with PABC usually present with a palpable mass, yet it is still reassuring that $73 \%$ to $88 \%$ of masses invasively evaluated in pregnancy are benign $[11,12]$

In our study we just included pregnant or lactating females presenting with palpable lumps and we found out that in the 100 patients included, 15 were malignant (15\%) and 85 were benign $(85 \%)$.

\section{Conclusion:}

Even though the majority of the pregnancyassociated breast masses are benign; a strict evaluation of any lesion is still required to exclude malignancy. Ultrasound is the optimal radiologic tool for assessing breast disorders in women during pregnancy and lactation.

\section{References}

1- NAVROZOGLOU I.., VREKOUSSIS T, KONTOSTOLIS E., et al.: Breast cancer during pregnancy: A mini-review. Eur. J. Surg. Oncol., 34: 837-43, 2008.

2- MOLCKOVSKY A. and MADARNAS Y.: Breast cancer in pregnancy: A literature review. Breast Cancer Res. Treat., 108: 333-38, 2008.

3- VAN NES J.G. and VAN De VELDE C.J.: The preferred treatment for young women with breast cancer-mastectomy versus breast conservation. Breast, 15 (Suppl 2): S3-S10, 2006. 
4- KEYSER C.P.T.E.A., STAAT M.B.C., FAUSETT C.O. L.M.B., et al.: Pregnancy-Associated Breast Cancer. Rev. Obstet. Gynecol., 5 (2): 94-9, 2012.

5- RODRIGUEZ A.O., CHEW H., CRESS R., et al.: Evidence of poorer survival in pregnancy-associated breast cancer. Obstet. Gynecol., 112: 71-8, 2008.

6- PARENTE J.T., AMSEL M., LERNER R., et al.: Breast cancer associated with pregnancy. Obstet. Gynecol., 71: 861-4, 1998.

7- LOIBL S., RING A., VON MINCKWITZ G., et al.: Breast cancer during pregnancy-a prospective and retrospective European registry (GBG-20/BIG02-03). (Meeting Abstracts) J. Clin. Oncol., 26 (May 20 Suppl): 22143, 2008.
8- THERIAULT R. and HAHN K.: Management of breast cancer in pregnancy. Curr. Oncol. Rep., 9: 17-21, 2007.

9- LENHARD M.S., BAUERFEIND I. and UNTCH M.: Breast cancer and pregnancy: Challenges of chemotherapy. Crit. Rev. Oncol. Hematol., 67: 196-203, 2008.

10- ROCHE N.: Follow-up after treatment for breast cancer in young women. Breast, 15 (Suppl 2): S71-S75, 2006.

11- NOVOTNY D.B.: Fine needle aspiration of benign and malignant breast masses associated with pregnancy. Acta Cytologica, 35: 676-86, 1991.

12- BYRD B.F. Jr., BAYER D.S., ROBERTSON J.C., et al.: Treatment of breast tumors associated with pregnancy and lactation. Ann. Surg., 155: 940-7, 1962.

\title{
تصوير سرطان سرطان الثلى المرتبط بالحمل
}

\author{
سرطان الثىى المرتبط بالحمل هو سرطان الثىى الذى يظهر إما آثناء الحمل آو فى السنة الأولى بعد الولادة.

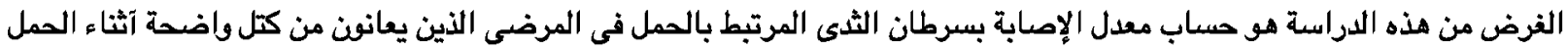

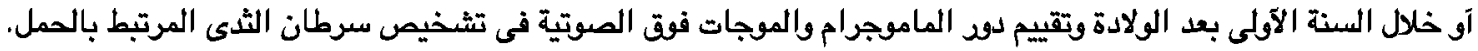

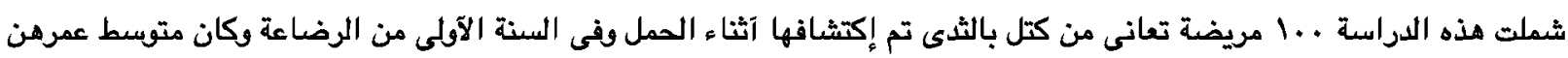

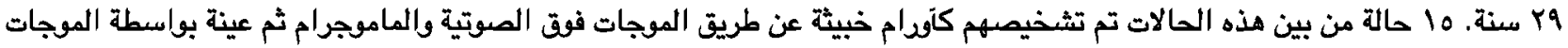

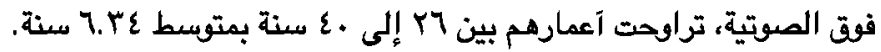 \\ على الرغم من آن غالبية كتل الثىى المرتبطة بالحمل حميدة، لا يزال هناك حاجة لإجراء تقييم صارم لإستبعاد وجود ودم خبيث. الموجات

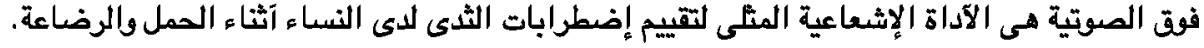

